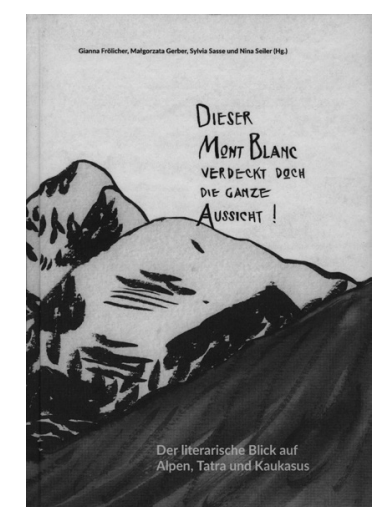

\title{
Mont Blanc zasłania cały widok
}

DOl: $10.19195 / 2084-4107.11 .36$

[rec.:] „Dieser Mont Blanc verdect doch die ganze Aussicht”. Der literarische Blick auf Alpen, Tatra und Kaukasus, Gianna Frölicher, Małgorzata Gerber, Sylvia Saase und Nina Sailer (Hg.) Mit Collagen von Nastasia Louveau. Aus dem Polnischen übersetz von Nina Sailer. Aus dem Russischen übersetz von Olga Bronnikowa. Edition Schublade Zürich 2016. Für German Ritz zum 65. Geburtstag.

Mont Blanc blocks the entire view

Słowa-klucze: Mont Blanc, Alpy, literatura, kultura

Keywords: Mont Blanc, Alps, literature, culture

Profesor German Ritz jest znanym szwajcarskim historykiem literatury, polonistą i slawistą, legitymującym się niezwykle poważnymi dokonaniami naukowymi przede wszystkim w zakresie literatury polskiej, jego prace zaś są dobrze znane i wysoko cenione w polskim środowisku polonistycznym. Po studiach (1972-1977) germanistycznych, rusycystycznych i romanistycznych odbytych na uniwersytetach w Zurychu i Genewie doktoryzował się pod kierunkiem wybitnego slawisty prof. Petera Branga (ur. 1924) na uniwersytecie w Zurychu w 1980 r. na podstawie pracy 150 Jahre russische Heineübersetzung. W następnych latach German Ritz poświęcił się głównie pracom polonistycznym i w 1989 r. habilitował się, przedstawiając ambitną monografię Die polnische Prosa 1956-1976, by zostać profesorem tytularnym w 1996 r. Uznanie w środowisku 
polonistycznym przyniosły mu dwie książki o Jarosławie Iwaszkiewiczu: Polskie spotkanie z Niemcami. Jarostaw Iwaszkiewicz i Stefan George (1998) oraz monografia Jarosław Iwaszkiewicz. Pogranicza nowoczesności (1999). Cały szereg jego nowatorskich prac zyskało mu chlubne miano ,patrona tematów trudnych”. Szczególną uwagę zwraca innowacyjność jego postawy metodologicznej, prowadzącej go do ciekawych konstatacji na temat literatury i kultury polskiej, a tu wskazać warto na jego sprawność w operowaniu metodami właściwymi badaniom typu „gender” (Nowa świadomość płci w modernizmie. Studia spod znaku gender w kulturze polskiej i rosyjskiej u schytku stulecia, 2000; Nić w labiryncie pożądania: gender i pleć w literaturze polskiej od romantyzmu do postmodernizmu, 2002; Kobiety w polskim romantyzmie a język ptci, 2009; Nowy polski tekst o Szwajcarii z perspektywy kobiet. Między romantyzmem a modernizmem, 2012). Miarę nowatorstwa warsztatu badawczego profesora Germana Ritza daje także jego odważna rozprawa (Kresy polskie w perspektywie postkolonialnej, 2008). Mądrze zauważa tu autor:

Postkolonialna lektura jest dla literatury polskiej na pewno ważną, teoretycznie podbudowaną platformą przeprowadzania własnych i cudzych rachunków sumienia. Może funkcjonować jako lektura dodatkowa, nie jako lektura podstawowa. Przedmiotem rozliczeń jest przede wszystkim historia, mianowicie historia władzy i roli, jaką odgrywa w niej literatura.

Ważną wreszcie rolę przypisać trzeba studiom profesora Ritza nad twórczością Juliusza Słowackiego (Poeta romantyczny i nieromantyczne czasy, 2011). Godnych uwagi, nowoczesnych pod względem metodologicznym i odkrywczych w swym charakterze prac polonistycznych profesora Ritza jest oczywiście więcej, ale tu już ich wymieniać nie będziemy, ponieważ to, co zostało wyżej powiedziane, tłumaczy dobrze, dlaczego - nawiązując do szlachetnej tradycji uniwersyteckiej - uczniowie, współpracownicy i przyjaciele profesora postanowili mu zadedykować specjalny tom studiów jako księgę dla uczczenia jego 65. urodzin.

W przeciwieństwie do większości tego rodzaju zbiorów studiów i artykułów, stanowiących wielotematyczny, mówiąc trochę złośliwie, „bróg nieplewiony”, autorzy tomu poświęconego Germanowi Ritzowi nadali mu charakter monotematycznej monografii poświęconej — mniej więcej jednolitej — problematyce górskiej, a ściślej mówiąc literackiemu rzutowi oka na Alpy, Tatry i Kaukaz. Niezwykle ciekawy tom zatytułowany został żartobliwie i przewrotnie „Dieser Mont Blanc verdect doch die ganze Aussicht”. Der literarische Blick auf Alpen, Tatra und Kaukasus. Słowa te są cytatem z Trazymeńskiego zająca Kazimiery Iłłakowiczówny, wykorzystanym w omawianym tomie w świetnej rozprawie Małgorzaty Gerber pt. Gedanken einiger Polen am Mont Blanc (s. 118, przypis 55), ale funkcję metakrytyczną wobec całego tomu poświęconego Germanowi Ritzowi pełnią one we wstępie do omawianego dzieła napisanym przez Giannę Frölicher 
i Sylvię Saase 1 . Ten wstęp jest ważny, zwraca bowiem uwagę na metodologiczne podstawy pisania o różnych górach, związane z odczuwaniem ich w kategoriach swojskości bądź obcości (casus Kazimiery Iłłakowiczówny, ale także Mikołaja Gogola i Lwa Tołstoja). Ten wątek przewija się w kilku pracach umieszczonych w omawianym zbiorze. Autorki wstępu zwracają więc uwagę, że odmienność sposobu widzenia Alp, Tatr i Kaukazu wynika w znacznej mierze z zastosowania w ich opisie aspektów estetycznych krajobrazu, ewokujących jego swojskość lub obcość. Ten aspekt problematyki sposobu widzenia gór - w szerszym rozumieniu kraju, w którym te góry się znajdują — odgrywa istotną rolę w kilku zamieszczonych w omawianym tomie pracach. Na czoło wysuwa się tu precyzyjna, prawdziwe piękna rozprawa Małgorzaty Gerber Gedanken einiger Polen am Mont Blanc. W erudycyjnej, znakomitej pod względem metodologicznym rozprawie, autorka dała poważną interpretację relacji Antoniego Malczewskiego z jego wejścia na Mont Blanc w 1818 r. Wykazując zaś ładną orientację w polskim stanie badań, przedstawiła sytuujące się „,zwischen Abstossung uns Anziehung” refleksje innych polskich pisarzy (Juliusz Słowacki, Zygmunt Krasiński, Antoni Edward Odyniec, Kazimiera Iłłakowiczówna) podejmujących zarówno motyw Mont Blanc, jak i szerzej widzianą problematykę alpejską. Warto zwrócić uwagę na to, że sporo uwagi poświęciła badaczka Krasińskiemu, co nie dziwi w świetle faktu, że jest ona autorką bardzo ważnej monografii Zygmunt Krasiński und die Schweiz. Die helvetischen Eindrücke in Leben und Schaffen des Dichters (ed. Peter Lang 2007). Końcowej części swej pracy nadała ona charakter do pewnej miary eseistyczny, co jednak nie umniejsza jej znaczenia, zgrabnie tu bowiem zarysowana została ważna konstatacja, że w tradycji literackiej stosunek do Mont Blanc sytuował się „zwischen Abstossung und Anziehung”. Sandro Zanetti w sposobie eseistycznego ujęcia problematyki górskiej poszedł jeszcze dalej, dokonując w szkicu Literarische Gratwanderungen. Von Petrarcas Gipfelgefühl zu Jelineks Alpenpanik odważnego, skrótowego przeglądu modelowych form ujmowania problematyki górskiej w rozległym przedziale czasowym: od Petrarki do Elfride Jelinek.

Tomas Grob w ciekawej rozprawie Vom Mont Blanc in die Steppe. Antoni Malczewski, die aufklärten Berge und die romantissche Ebene wykazał dobrą znajomość polskich badań nad romantycznymi aspektami problematyki górskiej, co nie oznacza, by okazał dla nich pełną aprobatę, dowodząc pełni ich zrozumienia, aczkolwiek rzetelnie je wykorzystał. W końcowej części swych rozważań wskazując na echa naukowych aspektów w późnym osiemnastowiecznym podróżopisarstwie, powiada on bowiem: „Vielleicht geht auch deswegen das polnische wie russische romantische Reisen in seinen etnographischen Interessen weit über

${ }^{1}$ G. Frölicher, S. Saase, Vorwort, [w:] „,Dieser Mont Blanc verdect doch die ganze Aussicht”. Der literarische Blick auf Alpen, Tatra und Kaukasus, Gianna Frölicher, Małgorzata Gerber, Sylvia Saase und Nina Sailer (Hg.) Mit Collagen von Nastasia Louveau. Aus dem Polnischen übersetz von Nina Sailer. Aus dem Russischen übwesertz von Olga Bronnikowa, Zürich 2016.

Góry, Literatura, Kultura 11, 2018

(C) for this edition by CNS 
die sentimentalistischen, $>$ Sterne'schen $<$ Vorbilder hinaus" (s. 137). Kontynuując zaś wywód, dodaje:

Der andere Aspekt beträfe die Verbindung zu einem 'Exotismus', inbesondere zu einem, der schwankt zwischen dem Fremden und den Eigenen, so wie er sich auch in der Steppe der ukrainischen Schule innerhalb der polnischen Romantik entfaltet. Die Verbindung zwischen den Alpen und der romantischen 'Exotic' ist discret, aber dennoch unübersehbar — und die Parallelisierung der Erstbesteigung eines Bergs mit einer Chinareise keineswegs zufällig. Die Berge wie überhaupt Landschaften werden romantisch faszinierender durch das Fremde, das Unbewohnte und Unwirtliche, in anderen Regionen Gelegene - Malczewskis selbstentfremdender Hinweis gegenüber Pictet auf »Ihre Berge« ('vos hautes montagnes, et vos charmantes vallées') kann diese Berge in ihrem poetischen Wert erhöhen. Manchmal fügt sich das Fremde romantischer Landschaften scheinbar in einen Rahmen des Eigenen - durch würde es den romantischen Lake District der Briten ohne Alpenerfahrung wohl so nicht geben. Die zusätliche Spannung eines auch kulturell-geographisch »Anderen« ist eine Bereicherung, wenn nicht Notwendigkeit des romantischen Landschaftserlebnisses. Der Realismus wird diese Erfahrung des Selbst im Fremden wieder in eine Entdeckung des Eigenen übertragen und das Fremde debei tilgen (s. 137-138).

Przypisanie romantycznemu widzeniu gór, nawet Alp, kategorii egzotyzmu jest co najmniej ryzykowne. Logiczna i słuszna jest koncepcja dostrzegania w Kaukazie wrót do Orientu (badania Renaty Gadamskiej-Serafin), natomiast europejskie Alpy, po których oprowadzali profesjonalni lub para-profesjonalni przewodnicy, i o których rozpisywały się różne „Handbooki” ${ }^{2}$, turystyka zaś tak wyglądała, jak opisali ją Łucja Rautenstrauchowa, Franciszek Wołowski, Włodzimierz Budzyński (Niemcy i Szwajcaria, Wilno 1856), Stanisław Egbert Koźmian, (Podróż nad Renem i Szwajcarii, Poznań 1877) i cały legion innych podróżopisarzy ${ }^{3}$, mogły budzić fascynację wielkością, grozą, potęgą, ale egzotykiem dla Polaków od dawna nie były, tak samo, jak ukraińskie stepy nie były orientalizmem (ten błąd się czasem popełnia). Dziwi nieco uwaga, jaką Thomas Grob w przypisie opatrzył cytowany tu wywód:

2 Zob. sonet Konstantego Gaszyńskiego Na jeziorze Thune w Szwajcarii, [w:] idem, Poezje, Lipsk 1868, s. 40.

${ }^{3}$ Por. E. Kolbuszewska, Romantyczne przeżywanie przyrody. Znaczenia, wartości, style zachowań, Wrocław 2007, s. 7-34 (rozdział „Codzienne powszechne oblicze podróżowania romantycznego”); S. Burkot, Polskie podróżopisarstwo romantyczne, Warszawa 1988. 
Hier gibt es Schwellenphänomene wie Seweryn Goszczyński (Dziennik podróży do Tatrów, Tagebuch der Reise in die Tatra, 1832), das eine Übertragung anderer Reiseinteressen — und einer langen Ukraineerfahrung — auf das »eigene«, Gebirge und die Bergbewohner vornimmt. Sowohl Kamionka-Straszakowa, Janina („Do ziemi naszej”. Podróże romantyków, Kraków 1988, 39ff; vgl. ihre Liste der »romantischen « Polenreisenden, ebd., 23 die zeitlich an Goszczyński, anscheließen, meist aber nicht mehr im eigentlichen Sinne zur Romantik gehören: Pol, Lenartowicz, Kraszewski etc.) wie auch Jacek Kolbuszewski mit seiner Vorliebe für die Tatra (Kolbuszewski Jacek, Góry in Stownik literatury XIX wieku, hg. v. Bachórz u. Kowalczykowa, Wrocław et al. 1994, 327) müssen den Romantikbegriff dazu über Gebühr dehnen (ibidem, s. 144, s. 67).

To prawda, że Seweryn Goszczyński pewne aspekty kultury podhalańskiej tłumaczył sobie w kontekście swojej wiedzy o Ukrainie i sam przyznawał, że wstępną szkołą sposobu przeżywania Tatr był dla niego pobyt w Sofiówce. Szkoda więc, że autor nie zna - w pewnym sensie klasycznej — pracy Marii Janion Kozacy i Górale 4 , widziałby bowiem wyraźniej, jak (nie tylko u Goszczyńskiego) mają się do siebie Tatry i Ukraina. Nie bardzo też wiadomo, dlaczego do Janiny Kamionki-Straszakowej miałoby się odnosić twierdzenie, że także ona musi „den Romantikbegriff dazu über Gebühr dehnen"...

Na wysokim poziomie widzieć trzeba rozprawę Petera Branga Das Wallis als poetisches Gefilde in polnischen Gedichten. Dostrzegając w Alpach Walijskich swoiste królestwo polskiej poezji, Brang przedstawił nie tylko wnikliwą interpretację wielu utworów romantycznych i młodopolskich, ale także zaprezentował inny aspekt swoich zdolności i dokonań twórczych. Ukazując wartości i znaczenia wszystkich godnych uwagi w zakresie obranego tematu utworów, nie ograniczył się do ich omówienia, ale przedstawił także własne ich przekłady na język niemiecki. Poszedł więc dalej niż w znakomitej swojej antologii Landschaft und Lyrik. Die Schweiz in Gedichte der Slaven. Einekommentierte Antologie (1998). Z polskiego punktu widzenia Brang ma tu podwójną zasługę. Do korpusu godnych uwagi wierszy wchodzących w zakres pojęcia literatury alpejskiej ${ }^{5}$ wprowadził on w ten sposób Władysława Tarnowskiego Wodospad w Verneyaz, Zenona Przesmyckiego Fale wodospadu Salanfy pod Vernayaz, Marii Poraskiej sonet Więc na Aletschhorn (to niewątpliwa nobilitacja poetki, której utwory Brang interpretuje z ogromną wnikliwością), wreszcie cały cykl Jana Kasprowicza Ze szczytu Eggishornu. Warto tu przytoczyć, dla zilustrowania tej uwagi o świetnej jakości translacji Branga, jego niemieckojęzyczną wersję sonetu Ality — Marii Poraskiej z jej tomu wierszy Helvetia (1912):

${ }^{4}$ W zbiorze Z dziejów stosunków literackich polsko-ukraińskich, Wrocław 1974, s. 135-169.

5 Por. C.E. Engel, La Littérature alpestre en France et en Angleterre au XVIII et au XIX siècle, Paris 1931, nowe wyd. 2009. 
Königreich der Stille und des Schweigens. Farbenwunder - möcht es doch gelingen, Jene Blöcke aus Granit zu zwingen Und den Gipfel furchtlos zügig zu ersteigen!

Silbernebel kreist in Eisengründen. Presst in Felsenrinnen seinen Odem. Trunken fällt der Blick ins Bodenlose, Das Gefühl des Dasseins droht zu schwinden.

Himmelsruh - nur fern über der Tiefe, wirbelt in den Nebeln Schneegestiebe und man hört gedämpftes Windespfeifen.

Westwärts dort, wo Wolkendecken hangen. Einem Schild gleich, einem blut'gen langen, feurig schwimmt hervor die Sonnenscheibe ${ }^{6}$.

Nie ulega wątpliwości, że interpretacje Branga pozwalają nieco wyżej, niż to czyniono dotychczas, oceniać wartość wierszy Tarnowskiego i Poraskiej, aczkolwiek z uśmiechem można też zauważyć, że niemiecka wersja sonetu Poraskiej sprawia wrażenie dojrzalszej od oryginału pod względem artystycznym. Z całą natomiast powagą warto zauważyć, że zarówno Małgorzacie Gerber, jak i Thomasowi Grobowi i Peterowi Brangowi zawdzięczamy wprowadzenie polskich prac naukowych o tematyce górskiej drukowanych w roczniku „Góry — Literatura - Kultura” do szeregu prac funkcjonujących w szerszym obiegu europejskim. Oczywiście podobną zasługę trzeba przypisać translatorom i edytorom polskich wierszy wprowadzonych do niemieckojęzycznych publikacji o tematyce alpejskiej — tu zasługę dzielą między siebie wybitny tłumacz Christoph Ferber ${ }^{7}$, Rolf Fieguth ${ }^{8}$ i wspomniany tu Peter Brang.

Z prac polskich autorów, które znalazły się w omawianym zbiorze studiów, największą wartość ma rozprawa Grażyny Borkowskiej „,Choucas”. Zofia Natkowskas Schweizroman. W tym studium wnikliwa analiza i interpretacja powie-

${ }^{6}$ M. Poraska, III. Los denn aufs Aletschhorn!, [w:] P. Brandg, Das Wallis als poetisches Gefilde in polnischen Gedichte. ,Dieser mont Blanc verdect doch die ganze Ansicht”, s. 69.

7 Przede wszystkim zbiór poezji Juliusza Słowackiego: Des Dichters grösster Ruhm: Ausgewählte Lyrik (1997), ale także antologia M. Konopnicka, W. Gomulicki et.al., Polnischer Realismus. Ein literarisches Lesebuch (1996), oraz wiersze różnych poetów w wielkiej antologii Petera Branga Landschaft und Lyrik — die Schweiz in Gedichte der Slaven (1998) — o tej antologii zob. J. Kolbuszewski, Szwajcarskie wiersze polskich poetów, „Wierchy” LXIV, 1998, s. 331-332.

${ }^{8}$ Rolf Fieguth (ur. 1941) — wybitny historyk literatury, autor cennych prac m.in. o Adamie Mickiewiczu (Rozpierzchte gałazki. Cykliczne i skojarzeniowe formy kompozycyjne w twórczości Adama Mickiewicza, 2002) i Witoldzie Gombrowiczu (Gombrowicz z niemiecka gęba i inne szkice komparatystyczne, 2012), thumaczył m.in. Translatlantyk Gombrowicza i wiersze Cypriana Norwida. W „Dieser Mont Blanc verdect doch die der ganze Aussicht!” umieścił trzy przekłady wierszy Juliana Przybosia. 
ści Nałkowskiej wzbogacona jest o ważne uwagi dotyczące sposobu widzenia Szwajcarii przez pisarkę:

In den Augen Nałkowskas ist die Schweiz der Zwischenkriegszeit. Ort eines ungewöhnlichen Experiments, wo Auspruchslosigkeit, Bescheidenheit und Arbeitsamkeit (die unter anderem in einer detailliert besschriebenen Begegnung mit einem Bauer festgehalten ist, der mit einem unbespannten Schlitten Holz vom Hang herunterbefördet und versichert, dass ihndiese Plackerei nicht sonderlicht ermüde: „Ça m'fatiq'pas beaucoup « sowie die Absschwächung anstelle einer Betonung und kultureller Unterschiede zur Ausarbeitung einer friendlichen Daseinformel gefürht haben?.

Przemysław Czapliński w studium Die Faltung der Berge. Zwei Schelmenabstiege dał ciekawe interpretacje prac Antoniego Kroha Sklep potrzeb kulturalnych i Spisków Wojciecha Kuczoka, ale ta wartościowa praca wskazująca na anachroniczność różnych aspektów mitologizacji świata polskich górali współczesnych na pewno lepsze zrozumienie znalazłaby u polskiego czytelnika niż u niemieckojęzycznego odbiorcy.

Poza kręgiem górskiej problematyki mieści się — mimo mylącego tytułu — poświęcony Włodzimierzowi Odojewskiemu szkic Ingi Iwasiów Ein Wochenende in den Bergen. Kilka prac dotyczy tu problematyki górskiej w pisarstwie autorów rosyjskich, m.in. Karamzina (Anna Krier, Berge des Begehrens. Karamzins russischer Reisender zwischen Rheinfall und Jungfrau; Tatjana Hofman, Svanetien in die Schweiz verwandeln. Trat'jakovs Reise durch Kaukasus). Zupełnie niezrozumiały jest powód, dla którego bardzo powierzchowny szkic Alfruna Kliemsa "Söhne der Tatra”. Slawisches Sehnen und tragische Abstürze: Der slowakische Fall opatrzony został mottem - cytatem z wiersza Juliana Przybosia Z Tatr. Rzecz ta dotyczy pobieżnego przeglądu utworów L'udovita Štúra związanych z Tatrami z zupełnym pominięciem roli, jaką symbolika Tatr odegrała w ideologii słowackiego odrodzenia narodowego. Całkowicie przypadkowe jest zestawienie z nimi wspomnianego w paru zdaniach zbioru wierszy Svetozára Hurbana Vajanskeho Tatry a more... Aleksander Markin w dzienniczku-szkicu Moи горы / Meine Berge opisał sympatycznie kilka swoich wycieczek alpejskich (m.in. Viamala-Schlucht), i tak jak literacki szkic Stefana Chwina o Szwajcarii otwiera cały omawiany tom, tak dziennik alpejski Markina go zamyka, rzec więc można, że te dwa literackie teksty spajają klamrą książkę poświęconą profesorowi Ritzowi w dniu jego 65. urodzin.

Jacek Kolbuszewski

9 G. Borkowska, ,Choucas” Zofia Nałkowskas Schweizroman, [w:] „Dieser Mont Blanc...”, s. 261. 
Góry, Literatura, Kultura 11, 2018

(C) for this edition by CNS 